\title{
Density Functional Theory Study on the Mechanism of Biochar Gasification in $\mathrm{CO}_{2}$
}

\section{Environment}

\author{
Hong Tian ${ }^{1}$, Zhengwen $\mathrm{He}^{1}$, Jiawei Wang ${ }^{2}$, Hao Jiao ${ }^{1}$, Zhangmao $\mathrm{Hu}^{1 *}$, Yang Yang ${ }^{2 *}$ \\ ${ }^{1}$ School of Energy \& Power Engineering, Changsha University of Science \& Technology, Changsha 410114, China \\ ${ }^{2}$ Bioenergy Research Group, EBRI, Aston University, Birmingham B4 7ET, UK. \\ Corresponding author: Y. Yang y.yang6@aston.ac.uk; Z. Hu: huzhangmao@ 163.com
}

\begin{abstract}
This work presents a comprehensive analysis on the $\mathrm{CO}_{2}$ gasification of Miscanthus derived biochar by using the combined experimental and computational methods. The empirical formula and 2D molecular model of the biochar were proposed based on the results from elemental analysis, Fourier infrared spectroscopy and solid-state ${ }^{13} \mathrm{C}-\mathrm{NMR}$ spectroscopy. The Density Functional Theory (DFT) method was used to study the conversion of biochar to the gaseous products under the $\mathrm{CO}_{2}$ condition at the b3lyp / 6-31g (d, p) level. The reactants, intermediates, transition states and products during the $\mathrm{CO}_{2}$ gasification process were analyzed and the activation energy $(\Delta E)$ of each reaction step and thermodynamic parameters (Gibbs free energy $\Delta G$ and Enthalpy $\Delta H$ ) were obtained. By comparing the kinetic and thermodynamic parameters of different reaction paths, it was found that the proposed Path 1 and Path 5 could occur spontaneously with the changes in Gibbs free energy $(\Delta G)$ being $182.6 \mathrm{~kJ} / \mathrm{mol}$ and $-170.6 \mathrm{~kJ} / \mathrm{mol}$, respectively. The order of the reaction path was Path $1<$ Path $5<$ Path $3<$ Path $4<$ Path 2, in terms of the degree of difficulty. It was also found that for the benzene ring having a ring-opening reaction, when the substituents were located in 2 and 3 carbon atoms or 2, 3 and 5 carbon atoms, the C-C bond between 1 and 6 carbon atoms was more prone to homolytic reaction than that between 1 and 2 carbon Atoms.
\end{abstract}

Keywords: Biochar Structure; $\mathrm{CO}_{2}$ Gasification; Density Functional Theory; Reaction Kinetics 


\section{Nomenclatures}

$\mathrm{C}_{f} \quad(\mathrm{Re})$ Active Carbon Site

$T \quad$ Reaction Temperature

$\Delta \mathrm{E} \quad$ Internal Energy

$\Delta \mathrm{E}_{0} \quad$ Internal Energy at the Ground State

$\Delta$ Eelec $_{\text {enternal Energy }}$

ZPE Zero Point Energy

$\Delta \mathrm{E}_{\text {trans }} \quad$ Translation Energy

$\Delta \mathrm{E}_{\mathrm{rot}} \quad$ Rotation Energy

$\Delta \mathrm{E}_{\mathrm{vb}} \cdot \quad$ Vibration Energy

$\Delta G \quad$ The Change in Gibbs Free Energy

$\Delta H \quad$ The Change of Enthalpy

$\Delta S$. The Change of Entropy

Abbreviations

DFT Density Functional Theory

MS Miscanthus

TGA Thermogravimetric Analysis

FTIR Fourier Transform Infrared Spectrometer

TS Transition States

\section{1. Introduction}

The raising concerns on energy security and environmental issues have caused significantly increased demand and consumption of renewable energy resource and been driving the technology innovation and development. Biomass, as the only renewable carbon source, is a significant part of the future energy matrix `. 
Gasification is an advanced thermal conversion process that can convert solid biomass into fuel gases that can be directly used in internal combustion engines and turbines for energy production. Conventional air blown gasification involves partial combustion of feedstock to raise the gasification temperature and generation $\mathrm{CO}$ and $\mathrm{CO}_{2}$. The former is a part of the syngas, while the latter is a precursor of $\mathrm{CO}$ as it can be reduced by the carbon in the char to produce $\mathrm{CO}$. The behavior of $\mathrm{CO}_{2}$ is a vitally important factor during the gasification process, as it determines the quality of the final product. Apart from the conventional process, $\mathrm{CO}_{2}$ could also be directly utilized instead of air as a gasification medium to enhance the overall carbon conversion rate and improve the quality of the final product. ${ }^{1}$ A number of experimental studies have been conducted to investigate the influence of the temperature, pressure, heating rate, mineral content, pore structure and catalyst on the gasification of biochar in $\mathrm{CO}_{2}$ atmosphere, ${ }^{1-9}$ and computational models have also been established to analyses the biochar reaction. ${ }^{10,11}$ These studies have provided experimental evidences on the feasibility of $\mathrm{CO}_{2}$ gasification of biochar and explanations on the complexity of the gasification process.

Density functional theory (DFT) is a widely applied computational chemistry technique, which can be used to explore the reaction mechanism at the molecular level. The DFT molecular modelling can provide various information (e.g. molecule energy and structure, transition state energy and structure, vibration frequency, thermochemical properties, bonding and chemical reaction energy, chemical reaction path), which is useful to understand the interactions between carbonaceous solids and gases at different temperatures. ${ }^{12}$ The DFT method has been used to research the reaction mechanism of the thermochemical conversion processes including pyrolysis and gasification. ${ }^{13-16}$ The DFT study on the mechanism of gasification normally involves two steps, including creation of the molecular model for the raw material and simulation of the gasification process to understand the decomposition 
mechanism. Xiao et al. ${ }^{17}$ reported the molecular structure of biochar based on aromatic clusters by applying solvent exfoliation, high-resolution transmission electron microscopy with Cs-correction and quadrupole time-of-flight mass spectroscopy. It is indicated that the basic molecular units of biochar and coke are aromatic clusters, which show disordered folding and accumulation. They also established the quantitative relationship between $\mathrm{H} / \mathrm{C}$ atomic ratio and the size of aromatic clusters by combining hundreds of published works on various biochar. ${ }^{18}$ Zhao et al. ${ }^{19}$ analyzed the molecular structure of biochar samples from corn straw and poplar leaf by elemental analysis and spectral techniques and established the molecular structure model based on the analysis. These studies provided useful methods for the construction of molecular structure model of biochar and protocols for the results verification.

Although the reactions of carbonaceous materials with $\mathrm{CO}_{2}$ have been studied using quantum chemical simulation methods, ${ }^{15,20,21}$ there is limited work on addressing the structural model of the specific biochar. Some previous works focused on the simulation of the chemical adsorption of the oxygen-containing gases on the surface of carbonaceous materials, ${ }^{22-24}$ which can be regarded as the first step in the $\mathrm{CO}_{2}$ gasification process. Montoya et al. ${ }^{25}$ used the DFT method to explore the process of CO molecule desorption from carbonyl surface species in the gasification and combustion of char. It was found that the spread of the desorption activation energy depended not only on the shape of the active site, but also on the aromatic character of the molecular model and the oxygen complex environment that surrounded the carbonyl group. The desorption was also part of the $\mathrm{CO}_{2}$ gasification process. Li et al. ${ }^{26}$ carried out ReaxFF simulation and DFT calculation for lignite and lignite- $\mathrm{CO}_{2}$ modelling with the main purpose to exploring the formation path of $\mathrm{CO}$ and the change of enthalpy and entropy during the process. It was suggested that most of the elementary reactions in the $\mathrm{CO}$ formation pathways were entropy increasing processes, and 
high temperature was favorable for these relations. However, this work ignored the problems related to the transition state structure in the reaction path. Roberts et al. ${ }^{27}$ used $7 \times 7$ and $11 \times 11$ parallelogram-shaped carbon structures as the char model, and conducted experimental measurements and DFT atomic modeling. The main purpose was to explore the chemical properties of active sites in char with different structures. The results showed that the mean nucleophilic Fukui function of the H-terminated char models and active sites located at similar edge positions decreased with increasing size of char molecules and followed the sequence of zigzag > armchair > tip active sites. However, this work ignored the influence of other functional groups in the char on the reaction mechanism.

Further to the previous research discussed above, this work was conducted to investigate the gasification mechanism of the miscanthus derived biochar under the $\mathrm{CO}_{2}$ environment by using the combined experimental and computational DFT methods. A 2D molecular structural model of the biochar was developed based on the results from elemental analysis, Fourier transform infrared spectroscopy and nuclear magnetic resonance analysis. The model described the functional groups existing in the biochar molecule, which is the basis for accurately describing the decomposition process of biochar and the subsequent gasification mechanism. Combined with experimental analysis, the specific reaction pathway of biochar $\mathrm{CO}_{2}$ gasification reaction was proposed, and then the density functional theory (DFT) was used to model the reactants, transition states, intermediates and products in the gasification process. The comprehensive kinetic and thermodynamic data of the gasification reaction path are presented. Different gasification reaction paths were analyzed and compared according to kinetic and thermodynamic parameters. The optimized reaction path was obtained. All the kinetics data and reaction pathway would be highly useful for computational modelling of the gasification process and reactor design. 


\section{Materials and methods}

2.1. Feedstock and the preparation of biochar

The Miscanthus was collected from a local farm in Changsha, China. The samples were milled and sieved to obtain fine particles smaller than $74 \mu \mathrm{m}$. The Miscanthus samples were firstly pyrolysed at $600{ }^{\circ} \mathrm{C}$ with a heating rate of $10{ }^{\circ} \mathrm{C} / \mathrm{min}$ in a tube furnace for carbonization. The final temperature was hold for one hour to ensure the samples were fully converted. The product biochar was sealed and stored for further analysis. Table 1 shows analyses of the Miscanthus and biochar samples on dry basis.

Table 1 Proximate, ultimate analysis of Miscanthus and biochar

\begin{tabular}{|c|c|c|c|}
\hline & & MS (wt. \%) & Biochar (wt, \%) \\
\hline Ultimate & $\mathrm{C}$ & 47.36 & 71.54 \\
\hline \multirow[t]{4}{*}{ analysis ${ }^{\text {a }}$} & $\mathrm{H}$ & 6.65 & 3.02 \\
\hline & $\mathrm{O}^{*}$ & 39.62 & 12.85 \\
\hline & $\mathrm{N}$ & 0.29 & 0.55 \\
\hline & S & 0.10 & 0.14 \\
\hline Proximate & Ash & 5.98 & 11.9 \\
\hline \multirow[t]{2}{*}{ analysis $^{\text {a }}$} & Volatile & 72.89 & 17.27 \\
\hline & Fixed carbon & 21.13 & 70.83 \\
\hline
\end{tabular}

${ }^{a}$ Dry basis, ${ }^{*}$ calculated by difference.

2.2. Building the molecular structure of biochar

The molecular structure of the biochar samples was determined by experimental characterization followed by computational simulation. The results were later verified. Firstly, a general empirical formula was obtained in accordance to the results of elemental analysis. Then the molecular structure model was determined based on the results from infrared spectrum analysis and solid ${ }^{13} \mathrm{C}-\mathrm{NMR}$ spectrum. The molecular structure model was 
constructed by ChemBioDraw Ultra software. Verification was conducted by comparing the experimental elemental composition and solid-state ${ }^{13} \mathrm{C}-\mathrm{NMR}$ spectra of biochar with the simulated biochar model. The simulation of solid-state ${ }^{13} \mathrm{C}-\mathrm{NMR}$ spectrum was achieved by using the MestReNova software.

\subsection{Biochar gasification and product analysis}

The $\mathrm{CO}_{2}$ gasification of the char samples were performed by using a Mettler Toledo TGA2 thermogravimetric thermal analysis system. The biochar samples were heated from room temperature to $900{ }^{\circ} \mathrm{C}$ under a pure carbon dioxide environment with a heating rate of $20{ }^{\circ} \mathrm{C} / \mathrm{min}$. The final temperature was held for $30 \mathrm{~min}$. The mass of each TG sample was $10 \pm$ 0.5mg. The TGA was coupled to a Bruker TEMSOR II Fourier transform infrared Spectrometer (FTIR), which was used to analyze the real-time gaseous products during the gasification process. The heated transfer line was maintained at $250{ }^{\circ} \mathrm{C}$ in order to avoid volatile condensation. The test range of FTIR absorption band was $4000-400 \mathrm{~cm}^{-1}$. The solidstate ${ }^{13} \mathrm{C}$-NMR spectra were measured by an Ascend 400 NMR analyzer with a frequency of 100.63 MHz, a spectral width of $100 \mathrm{KHz}$ and a pulse width of $4 \mu$ s. The spectra probe was solid double resonance probe. Acquisition conditions were $0.0051 \mathrm{~s}$ sample time and a scan number of 4096. Peak groups were interpreted as follows: 0-50 ppm, alkyl-C; 50-110 ppm, O-alkyl-C; 110-165 ppm, aryl-C; 165-190 ppm, carboxyl-C; and 190-230 ppm, carbonylC. ${ }^{19}$ All experiments were repeated three times and the average results were taken to ensure the reproducibility of the results. During the experiment, we used well calibrated equipment and endeavored to strictly follow the standard experimental procedure and conditions in order to minimize the system and random errors. It is reported that the standard relative error of the TG-IR experiment results is less than $4 \%$, and the relative error of the solid-state 13C-NMR experiment results is less than $3 \%$. 


\subsection{DFT modelling of $\mathrm{CO}_{2}$ gasification process}

The general process of $\mathrm{CO}_{2}$ reduction with carbon can be described by the following Equations (1)- (4).

Initially, the $\mathrm{CO}_{2}$ gas molecule is chemisorbed on the active site $\mathrm{C}_{f}$ on the char surface ${ }^{28}$

$$
\mathrm{C}_{f}+\mathrm{CO}_{2} \rightarrow \mathrm{C}_{f}\left(\mathrm{CO}_{2}\right)
$$

This is followed by dissociation of the adsorbed $\mathrm{CO}_{2}$ to form $\mathrm{CO}$, and an oxygen surface complex $C_{f}(\mathrm{O})$ (e.g. quinone) on the char surface, as shown in Eq. (2),

$$
\mathrm{C}_{f}\left(\mathrm{CO}_{2}\right) \rightarrow \mathrm{C}_{f}(\mathrm{O})+\mathrm{CO}
$$

The subsequent formation of additional $\mathrm{CO}$ molecules is resulted from the O-complex decomposition, which interacts with the solid carbon on the char surface to give $\mathrm{CO}$ molecules, shown in Eq. (3). Montoya et al. ${ }^{29}$ demonstrated that the six-membered ring containing the O-complex underwent bond weakening and broken to form the $\mathrm{CO}$ gas molecule. After the loss of $\mathrm{CO}$, this ring may collapse to form a five-membered ring, or accompany the formation of a defect, which would act as another active carbon site to continue the process of $\mathrm{CO}_{2}$ gasification.

$$
\mathrm{C} f(\mathrm{O}) \rightarrow \mathrm{CO}
$$

The process shown in the Equations(1)-(3) can combine to give the Boudouard reaction, shown in Eq. (4).$^{30}$ The mechanisms, however, include intermediate reactions associated with the bond weakening, breaking, and re-arrangements.

$$
\mathrm{C}+\mathrm{CO}_{2} \rightarrow 2 \mathrm{CO}
$$

The DFT method has been effectively applied to calculate and analyze the electronic structure of large molecular system in the previous research. ${ }^{31}$ In this work, the DFT calculation was based on the B3LYP (Becke's three parameter gradient corrected exchange 
functional with the gradient corrected correlation function ${ }^{32}$ ) and 6-31G(d, p) basis set ("6$31 \mathrm{G}$ " is an expression of splitting valence bond basis set. "d" and "p" are addition polarization functions of carbon and hydrogen, respectively ${ }^{33}$ ), which consists of optimizing the equilibrium geometries including reactants, intermediates, products and the transition states. The Transition States (TS) method was employed to identify each the transition state during the gasification to ensure that each transition state has only one unique virtual frequency. The transition state was verified by using the Intrinsic Response Coordinate (IRC) method.

Thermodynamic data including changes of enthalpy $(\Delta H)$ and the Gibbs free energy $(\Delta G)$ were calculated to identify the priorities of the reaction pathways.

The change of Enthalpy was calculated by the following equations:

$$
\Delta H=\Delta \mathrm{E}+\mathrm{nR} T
$$

$$
\Delta \mathrm{E}=\Delta \mathrm{E}_{0}+\Delta \mathrm{E}_{\text {trans }}+\Delta \mathrm{E}_{\mathrm{rot}}+\Delta \mathrm{E}_{\mathrm{vb}}
$$

$$
\Delta \mathrm{E}_{0}=\Delta \mathrm{E}_{\text {elec }}+\mathrm{ZPE}
$$

where, $\mathrm{n}$ is the number of moles of gas, $\mathrm{R}$ is molar gas constant, $T$ is temperature, $\Delta \mathrm{E}$ is the internal energy, $\Delta \mathrm{E}_{0}$ is the internal energy at the ground state, $\Delta \mathrm{E}_{\text {elec }}$ is internal energy, $\mathrm{ZPE}$ is zero point energy, $\Delta \mathrm{E}_{\text {trans }}$ is translation energy, $\Delta \mathrm{E}_{\text {rot }}$ is rotation energy, and $\Delta \mathrm{E}_{\mathrm{vb}}$ is vibration energy.

The change in Gibbs free energy calculation equation:

$$
\Delta G=\Delta H-T \cdot \Delta S
$$

where, $\Delta G$ is the change in free energy, $\Delta H$ is change of enthalpy. $T$ is reaction temperature, $\Delta S$ is the change of entropy. 
According to the thermodynamics laws, when $\Delta H<0$, the reaction is exothermic; and when $\Delta H>0$, is the reaction is endothermic. When $\Delta G<0$, the reaction can occur spontaneously; and when $\Delta G>0$, the reaction cannot occur spontaneously $\Delta G$. The value of $\Delta G$ determines the conversion rate of reaction in equilibrium state.

According to the Transition State Theory, the activation energy is the minimal potentialenergy difference between transition state and reactants in ground state. ${ }^{34}$ The temperature has a minor impact on the thermodynamic performance; it was therefore not accounted in the calculation of the activation energy $E_{0}$. For free radical reactions, the bond dissociation energy was considered equaling to the activation energies. All processes was calculated at default condition $(298 \mathrm{~K}, 0.1 \mathrm{MPa})$ in Gaussian 16 suites of programs. ${ }^{35}$

\section{Results and discussion}

\subsection{Biochar analysis}

As shown in Table 1, the Miscanthus biochar contains more than $71 \%$ carbon, 3\% hydrogen and about $12 \%$ oxygen with trace amount of nitrogen and sulfur on the dry basis. This implies that oxygen will have much greater impact on the formation of active sites than nitrogen and sulfur. To simplify the char model, nitrogen and sulfur were not considered in the construction of the biochar molecular model. Initially the empirical formula of the conceptual model was normalized to 1 carbon atoms: $\mathrm{C}_{1} \mathrm{H}_{\mathrm{X}} \mathrm{O}_{\mathrm{Y}}$. The normalizing coefficients were then calculated according to the experimental elemental compositions and the molecule weight of the elements. The derived biochar empirical formula is $\mathrm{C}_{1} \mathrm{H}_{0.51} \mathrm{O}_{0.13}$. According to the quantitative relationship between the $\mathrm{H} / \mathrm{C}$ atomic ratio and the size of aromatic clusters established by Xiao et al. ${ }^{18}$, the aromatic cluster contains about 70 carbon atoms. Considering the carbon atoms contained in other functional groups, the number of carbon atoms in this model was determined to be 77 . It should be noted that the ash content was not considered 
when deriving the empirical formula for biochar. The obtained biochar empirical formula is therefore $\mathrm{C}_{77} \mathrm{H}_{39} \mathrm{O}_{10}$.

\subsection{Infrared spectrum analysis of biochar}

Fig. 1 shows the infrared spectrum of the biochar. The band assignments of the functional groups are shown in Table 2. There is a wide and strong band between 3800-3200 $\mathrm{cm}^{-1}$, meanwhile, a relative week peak presented at $1000-1260 \mathrm{~cm}^{-1}$ (CO stretching). This implies that the hydroxyl groups of alcohols, phenols and carboxylic acids are relatively insignificant, hence the main -OH groups were from water. ${ }^{36}$ The weak peaks at $3000-2850$ $\mathrm{cm}^{-1}$ and $1460-1375 \mathrm{~cm}^{-1}$ are related peaks, indicating the presence of a small amount of aliphatic CHx. The peak at $1720-1690 \mathrm{~cm}^{-1}$ indicates the presence of carbonyl or carboxyl groups in biochar. The peak at $1032 \mathrm{~cm}^{-1}$ is due to the aromatic ring stretching vibration or C-O stretching vibration, which indicates the existence of ether bonds. Since the saturated fatty ethers are not stable, the cyclic ethers are the dominant groups. The peak at 900-670 $\mathrm{cm}^{-1}$ corresponds to external bending vibration above the aromatic ring. The number, position and intensity of these absorption peaks depend on the number, position and nature of the substituents of the aromatic ring, $880-860 \mathrm{~cm}^{-1}$ and $810 \mathrm{~cm}^{-1}$ represent the one adjacent $\mathrm{H}$ deformation and the two adjacent $\mathrm{H}$ deformations, respectively. This indicates that the substituents on the aromatic ring are mostly 3-substituted and 4-substituted, where the position of the 3 -substituted substituent is mainly $(1,2,4)$, and the position of the 4 substituted substituent is mainly $(1,2,3,5)$. 


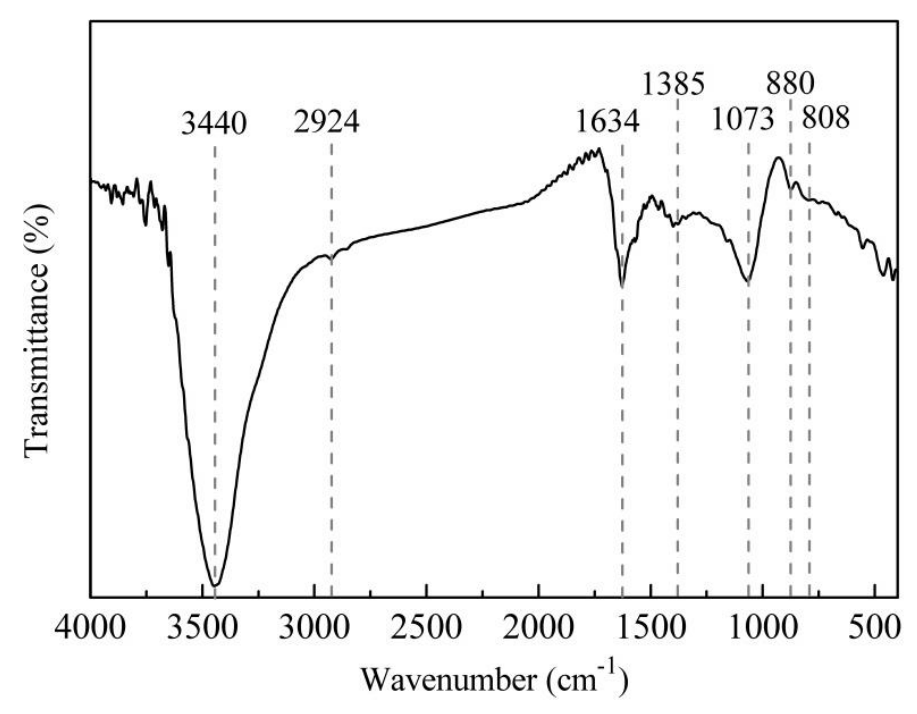

Fig. 1 FTIR spectrum of biochar

From the results of infrared spectrum analysis, the main functional groups within the macromolecular structure of the biochar can be derived. The side chains are mainly aliphatic hydrocarbons, with an average carbon number of one. The oxygen-containing groups exist mainly in the form of hydroxyl groups and ether groups. The hydroxyl groups mainly present in the form of phenolic hydroxyl groups. The ether structure presents in the form of phenoxy, phenhydroxy and methoxy groups with limited carbonyl groups. Most of the substituents on the aromatic ring are 3 and 4 substitutions, where the positions of the 3 substituted substituents are $(1,2,4)$, while the positions of the 4 substituted substituents are $(1,2,3,5)$.

Table 2 Band assignments of the most prominent peaks in the FT-IR spectra of biochar samples. ${ }^{37-40}$

Wavenumber $\left(\mathrm{cm}^{-1}\right) \quad$ Assignments

$3400-3320$

-OH stretching vibration

2923

Aliphatic $\mathrm{CH}_{3}$ asymmetric stretching vibration

Aliphatic $\mathrm{CH}_{2}$ asymmetric stretching vibration 
$1720-1690$

$1670-1600$

1460

$1380-1375$

$1300-1100$

1032

$880-860$

810

\section{Conjugated aromatic $\mathrm{C}=\mathrm{O}$}

Aromatic ring stretching $\mathrm{C}=\mathrm{O}$ or $\mathrm{C}=\mathrm{C}$

Aliphatic chains $\mathrm{CH}_{3}-, \mathrm{CH}_{2}-$

Aliphatic chains $\mathrm{CH}_{3}-$

Hydroxybenzene, aether, C-O, C-C, - OH

Aromatic ring stretching vibration or $\mathrm{C}-\mathrm{O}$ stretching vibration

Aromatic nucleus $\mathrm{CH}$, one adjacent $\mathrm{H}$ deformation

Aromatic nucleus $\mathrm{CH}$, two adjacent $\mathrm{H}$ deformation

\subsection{Solid-state ${ }^{13} \mathrm{C}-\mathrm{NMR}$ analysis of biochar}

Fig.2 (a) presents the solid-state ${ }^{13} \mathrm{C}-\mathrm{NMR}$ spectra of the measured of biochar prepared at $600{ }^{\circ} \mathrm{C}$. The spectra of biochar showed a broad signal spanning from 90 to $160 \mathrm{ppm}$, with the predominant component centered at $123 \mathrm{ppm}$. The $110-165 \mathrm{ppm}$ region attributed to aromatic carbon and the peak around 72 ppm was most likely due to methoxyl groups and ether-bound aliphatic carbons. For biochar, the amount of aromatic carbons was $74.47 \%$. Table 3 lists the percentage of the area for each functional group presented. 


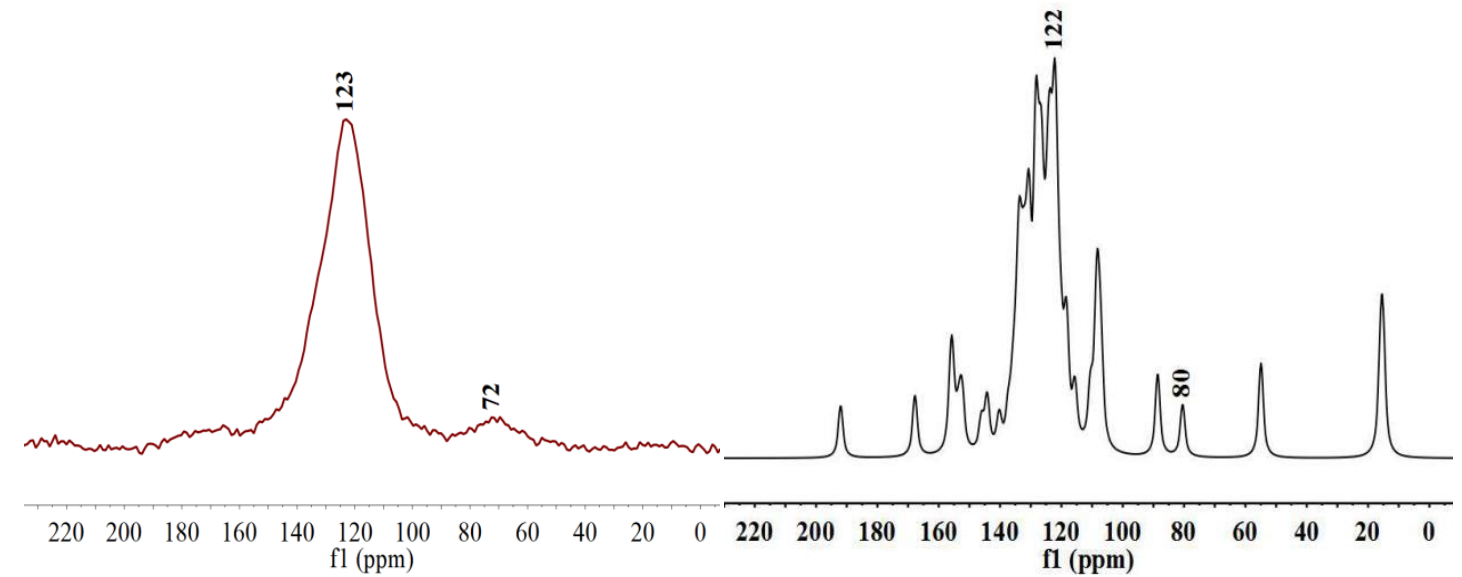

(a)

(b)

Fig. 2 Measured and simulated solid-state C-13 NMR spectra of biochar

(a) Experimental result; (b) Simulated result

\subsection{Molecular structural verification}

Considering the analysis results of element analysis, FTIR and solid-state ${ }^{13} \mathrm{C}-\mathrm{NMR}$ spectra, and in order to obtain the model structure, which is most consistent with the structure of biochar, the empirical formula is modified appropriately. The final empirical formula is $\mathrm{C}_{77} \mathrm{H}_{44} \mathrm{O}_{11}$. The final 2D molecular structure model is shown in Fig 4. In order to verify this structural model, the solid-state ${ }^{13} \mathrm{C}-\mathrm{NMR}$ spectrum of the biochar structure was simulated by using the MestReNova software. The result is shown in Fig 2 (b). Since the area under the NMR spectrum is directly proportional to the number of nuclei providing this area, the proportion of different chemical functional groups of the measured and simulated biochar models was calculated from solid-state ${ }^{13} \mathrm{C}$-NMR spectra. The comparison results are shown in Table 3. It can be seen that the chemical functional groups obtained by experimental means are close to those of the simulated biochar model in both types and quantities. The results of simulated elemental results are in a close agreement with the actual analysis carried out with the real sample. This suggests that the proposed $2 \mathrm{D}$ structural model is aligned to the 
measurement data and can be a valid representation of the char structure. This biochar structure model is used for further pyrolysis mechanism analysis.

Table 3 Verification of the simulated model

\begin{tabular}{llll}
\hline & & Biochar & Simulated Model \\
\hline Empirical formula & & $\mathrm{C}_{77} \mathrm{H}_{39} \mathrm{O}_{10}$ & $\mathrm{C}_{77} \mathrm{H}_{44} \mathrm{O}_{11}$ \\
& $\mathrm{C}(\%)$ & 71.54 & 71.53 \\
Elemental compositions & $\mathrm{H}(\%)$ & 3.37 & 3.40 \\
& $\mathrm{O}(\%)$ & 13.19 & 13.61 \\
Alkyl-C & $\delta 0-50$ & 2.52 & 6.10 \\
O-alkyl-C & $\delta 50-110$ & 16.52 & 15.45 \\
Aryl-C & $\delta 110-165$ & 74.47 & 74.58 \\
Carboxyl-C & $\delta 165-190$ & 4.26 & 2.26 \\
Carbonyl-C & $\delta 190-230$ & 2.23 & 1.61 \\
\hline
\end{tabular}

3.5 $\mathrm{CO}_{2}$ gasification and subsequent reaction kinetics analysis

Fig 3 shows the TG curve and the trace of the main gasification products $\left(\mathrm{CO}\right.$ and $\left.\mathrm{CH}_{4}\right)$ during the $\mathrm{CO}_{2}$ gasification of biochar. The $\mathrm{CO}_{2}$ gasification process includes three stages, namely drying, steady and gasification stages. After drying, the TG curve was stable from 100 to $650{ }^{\circ} \mathrm{C}$ with negligible mass loss. The main gasification reaction occurred from $650{ }^{\circ} \mathrm{C}$ with the highest weight loss rate after $900{ }^{\circ} \mathrm{C}$.

The FTIR analysis showed the tendency of gas products during gasification. The gasphase products is mainly $\mathrm{CO}$ and $\mathrm{CH}_{4}$ (the absorbance peaks are 2180 and $3015 \mathrm{~cm}^{-1}$, respectively), The yield of other gases (i.e. $\mathrm{H}_{2} \mathrm{O}, \mathrm{H}_{2}, \mathrm{CO}_{2}$ ) was not measured, as their yields are normally extremely low, being almost two orders of magnitude different as indicated by Sikarwar et al and Lahijani et al. ${ }^{41,42}$ According to the Beer-Lambert law, the absorbance of 
the gas product measured by FTIR is directly proportional to its concentration. The gas release curve indicates a very small amount of $\mathrm{CH}_{4}$ was produced during gasification. The $\mathrm{CO}$ release however, was negligible when the temperature was below $650{ }^{\circ} \mathrm{C}$ but began a sharp increase thereafter. This meant $650{ }^{\circ} \mathrm{C}$ is the zero boundary temperature. Upon reaching $900{ }^{\circ} \mathrm{C}$ with a hold time for 3 minutes, both the DTG and CO release curves reached peaks at the same point. This was due to the intensive Boudouard reaction taking place at high temperature.

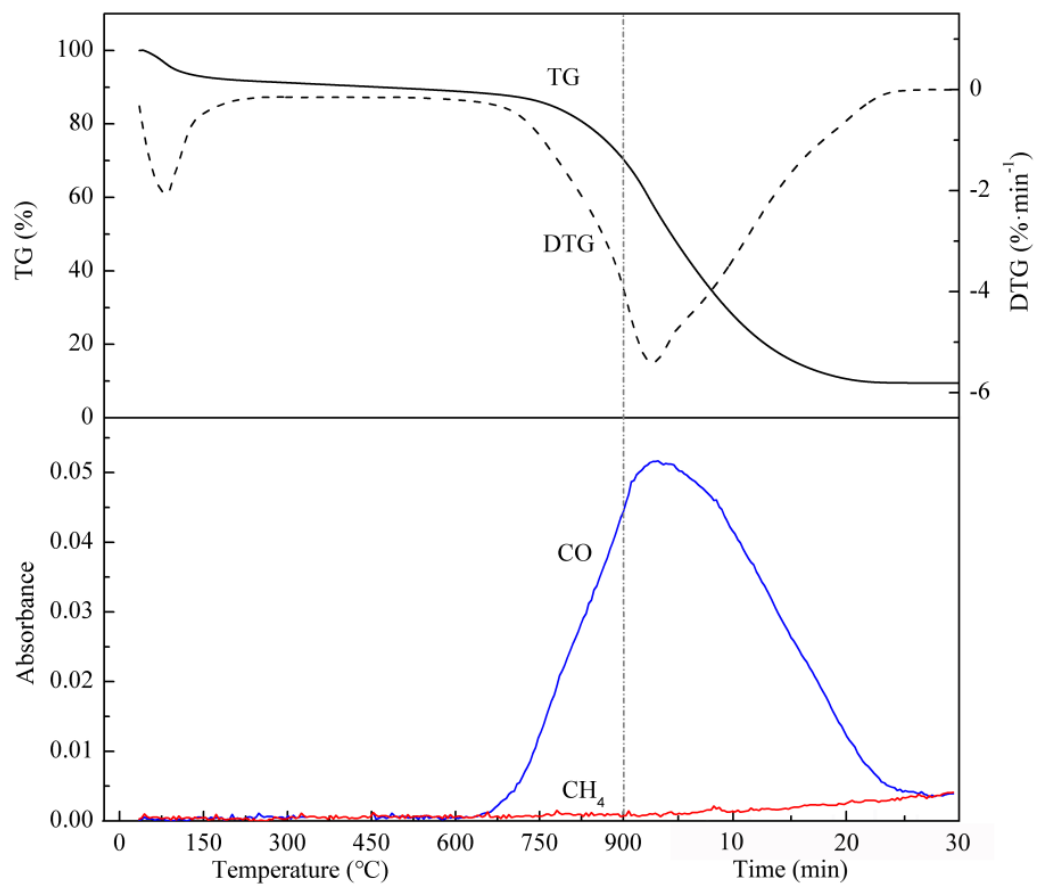

Fig.3 Results of TGA and in situ FTIR for gas release

3.6. Dynamics analysis of the $\mathrm{CO}_{2}$ gasification reactions

\subsubsection{Reaction pathways of $\mathrm{CO}_{2}$ gasification}

The proposed conceptual 2D molecular structural model, as shown in Fig.4, consists of a series of benzene and heterocyclic ring structure, which are connected by $\mathrm{C}-\mathrm{C}$ single bonds. Considering that the bond energy of C-C single bonds is significantly lower than that of benzene and heterocyclic structures bond energy. According to the structure, the designed gasification reaction path can be considered in two stages. The first stage is the homogeneous 
cleavage of the $\mathrm{C}-\mathrm{C}$ single bond, in which the active site and permanent gases were formed (shown in Fig 4). The second stage, shown in Fig 5, is the $\mathrm{CO}_{2}$ reduction, in which it includes three steps, namely $\mathrm{CO}_{2}$ chemisorption on reactive edge, the loss of first $\mathrm{CO}$ gas molecule through dissociation of adsorbed $\mathrm{CO}_{2}$ molecule, and the formation of the second $\mathrm{CO}$ gas molecule. The reduction process is repeated continuously during the gasification process until the entire gasification process is completed. Both the part 1 and part 5 form only one active site, hence each has only one reaction path. When forming the second $\mathrm{CO}$ molecule, there are two ways for bond breaking, which will form a competitive reaction. Part 2, Part 3 and Part 4 have two active sites, and each have two reaction pathways. Table S1 in the Supplementary Materials shows the equilibrium geometries of partial reactants, intermediates and partial transition states after optimizing and lists the key structure parameter of the species, including bond length, bond angle and dihedral angle. In order to facilitate the study of the related laws of the ring-opening reaction, the $\mathrm{C}$ atoms of the benzene ring in the molecules that are about to undergo the ring-opening reaction are numbered, and the ketone $\mathrm{C}$ atom is number 1 , and they are numbered in order along the direction of the substituent.

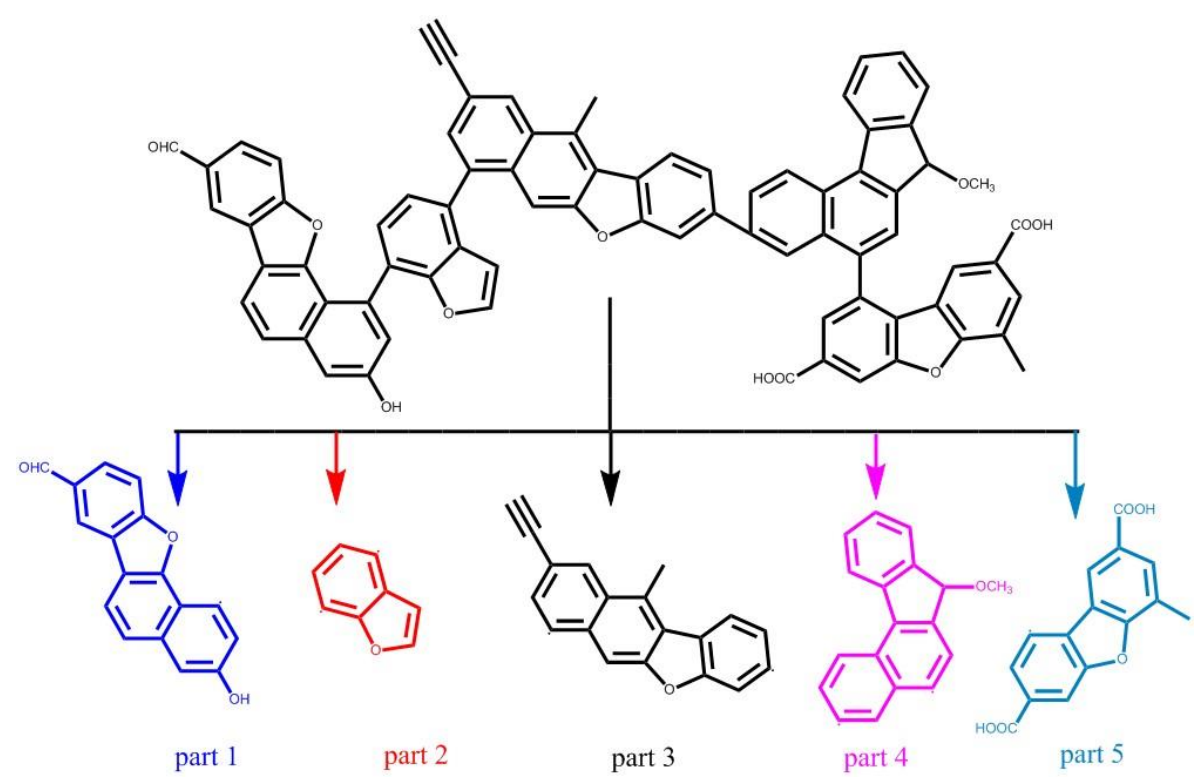

Fig.4 Initial gasification pathway of conceptual molecular structure 


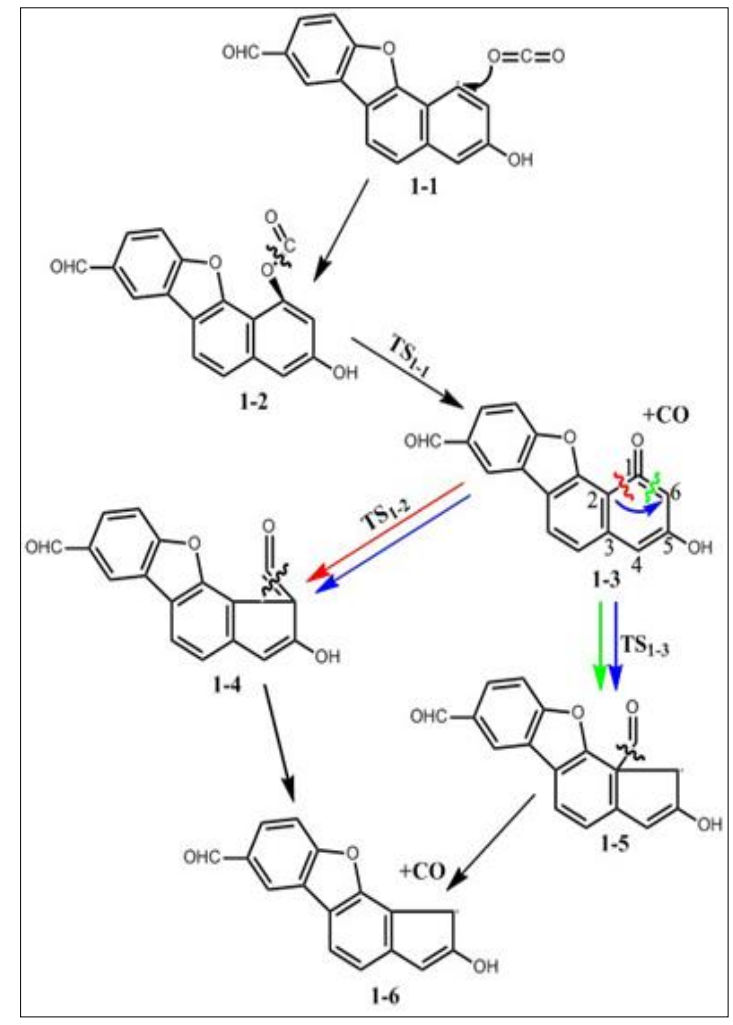

(a) subsequent reaction of part 1

(Path 1)

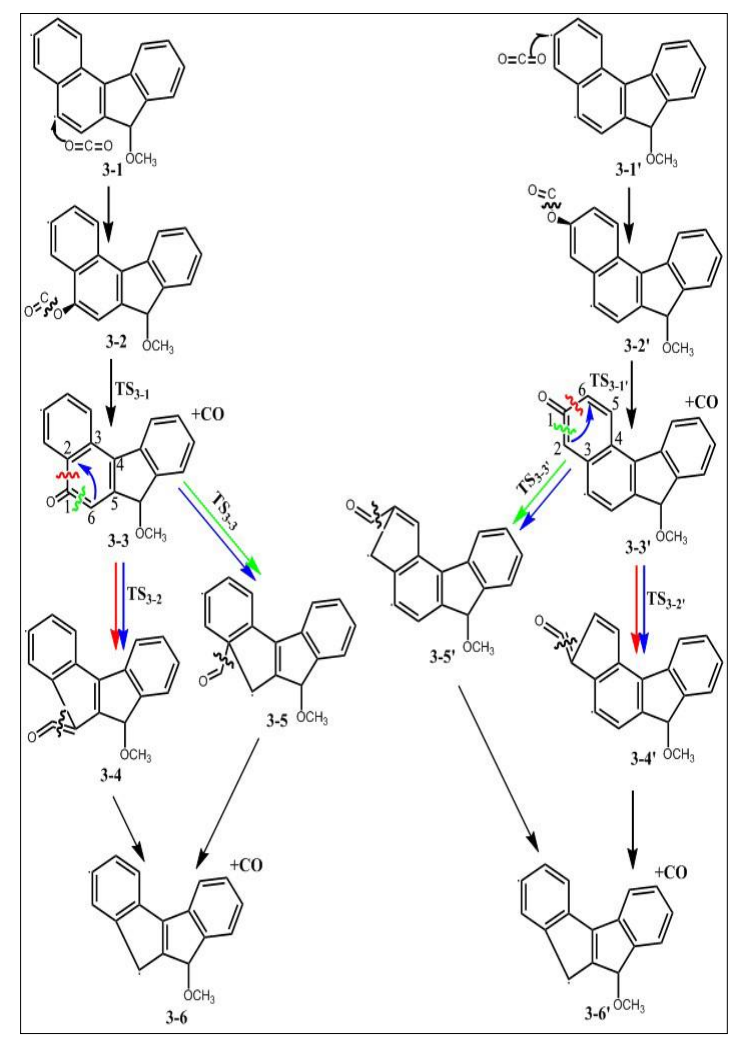

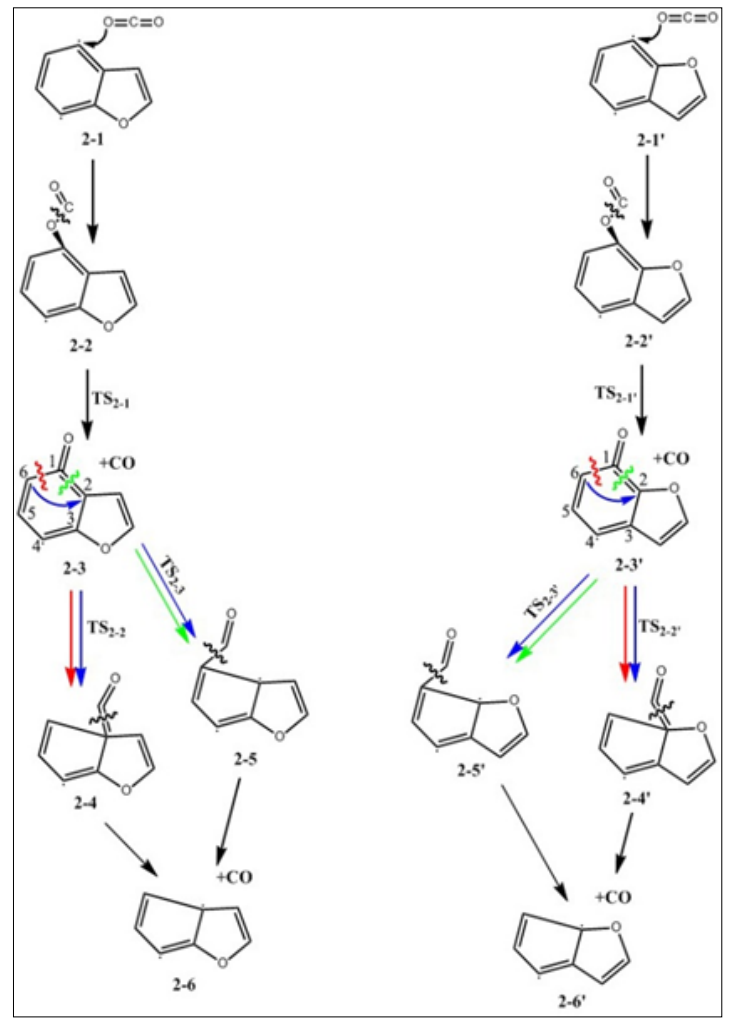

(b) subsequent reaction of part 2

(Path 2)

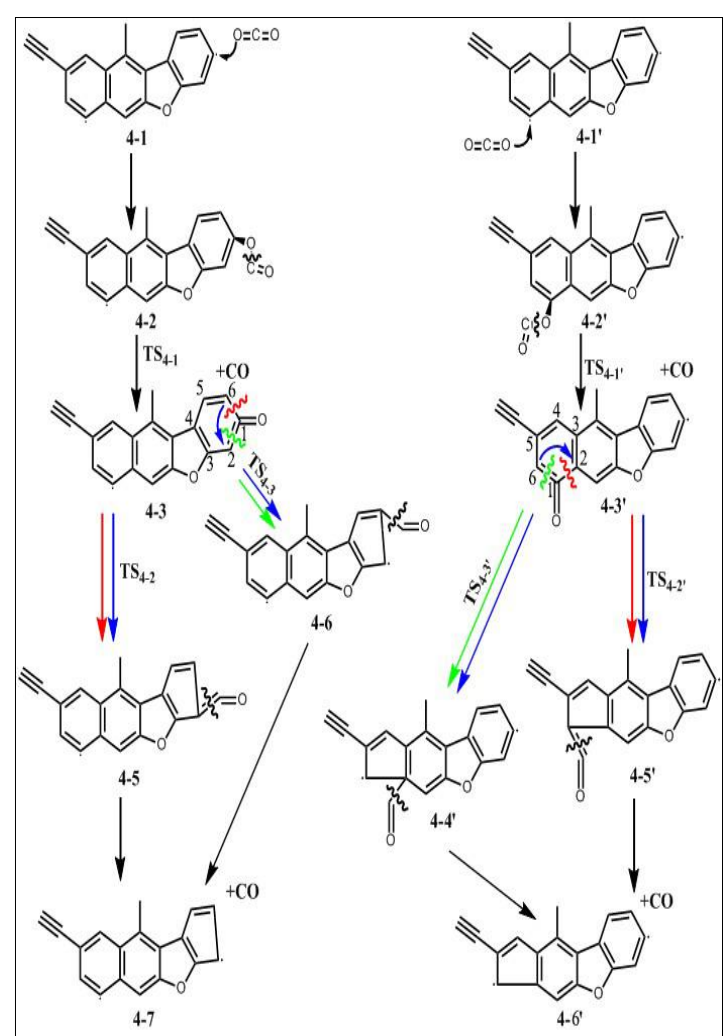


(c) subsequent reaction of part 3

(Path 3) (d) subsequent reaction of part 4

(Path 4)

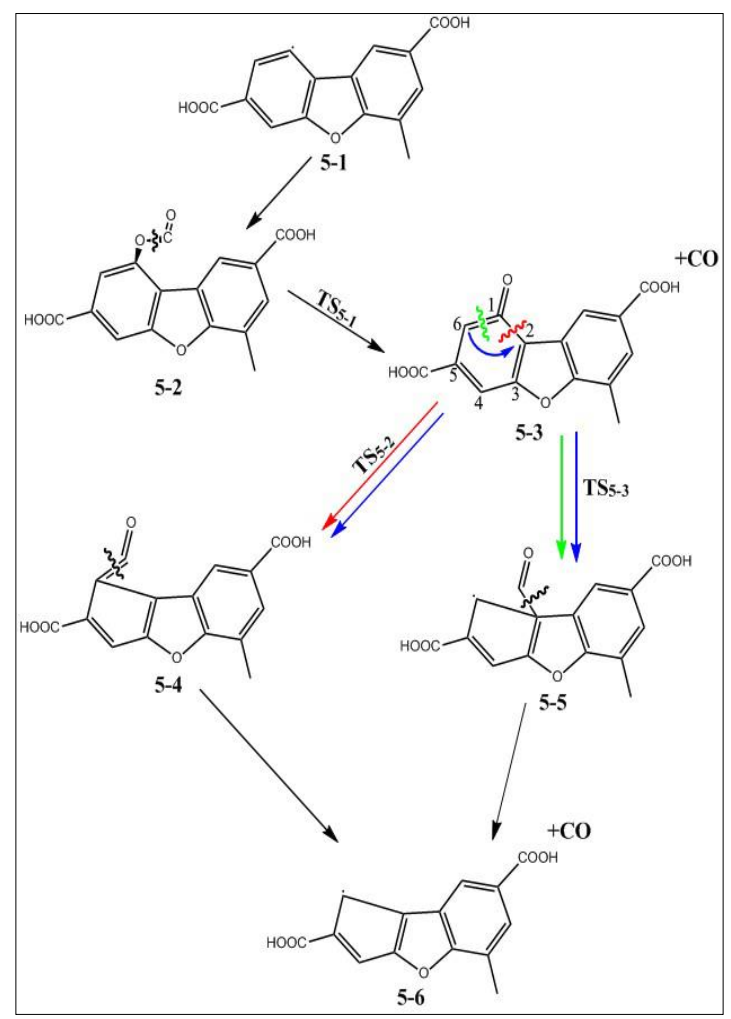

(e) subsequent reaction of part 5 (Path 5)

Fig.5 subsequent reaction of conceptual molecular structure

\subsubsection{Thermodynamics analysis of the decomposition reactions}

Table 4 shows thermodynamic parameters of each reaction path. The results indicate that the Path 1 (subsequent reaction of part 1) and Path 5 are able to occur spontaneously, because their $\Delta G$ are less than zero. By comparing the $\Delta G$ of each reaction pathway, it can be found that the order of $\Delta G$ value is Path $1<$ Path $5<$ Path $3<$ Path $4<$ Path 2 . It also shows that, in different temperature range, the production of $\mathrm{CO}$ was originated from different reaction paths. In the low temperature stage $\left(<800{ }^{\circ} \mathrm{C}\right), \mathrm{CO}$ was mainly produced follow the path 1 . And, after this stage, the CO produced is mainly from path 2. Path 1 is an exothermic reaction, as its $\Delta H$ value is negative $(-91.7 \mathrm{~kJ} / \mathrm{mol})$, while Path 2, Path 3 and Path 4 are endothermic 
reactions. For Path 2 , the $\Delta H$ value of the pathway $2-2^{\prime} \rightarrow 2-6^{\prime}$ is lower than that of $2-2 \rightarrow 2-6$, which is $924.8 \mathrm{~kJ} / \mathrm{mol}$. The $\Delta H$ of the pathway $3-2 \rightarrow 3-6$ in Path 3 is lower comparing to $3-$ $2^{\prime} \rightarrow 3-6$ ', which is $371.6 \mathrm{~kJ} / \mathrm{mol}$. For Path $4, \Delta H$ of the pathway $4-2 \rightarrow 4-6$ in Path 4 is lower comparing to $4-2^{\prime} \rightarrow 4-6$ ', which is $453.7 \mathrm{~kJ} / \mathrm{mol}$.

Table 4 Thermodynamic parameters of each reaction pathway

\begin{tabular}{|c|c|c|c|}
\hline \multirow{2}{*}{\multicolumn{2}{|c|}{ Pathway }} & \multicolumn{2}{|c|}{ Thermodynamic parameters $(\mathrm{kJ} / \mathrm{mol})$} \\
\hline & & $\Delta H$ & $\Delta G$ \\
\hline Path 1 & $1-2 \rightarrow 1-6$ & -91.7 & -182.6 \\
\hline \multirow{2}{*}{ Path 2} & $2-2 \rightarrow 2-6$ & 930.0 & 842.0 \\
\hline & $2-2^{\prime} \rightarrow 2-6^{\prime}$ & 924.8 & 837.8 \\
\hline \multirow{2}{*}{ Path 3} & $3-2 \rightarrow 3-6$ & 371.6 & 300.7 \\
\hline & $3-2^{\prime} \rightarrow 3-6^{\prime}$ & 441.6 & 366.1 \\
\hline \multirow{2}{*}{ Path 4} & $4-2 \rightarrow 4-6$ & 453.7 & 372.6 \\
\hline & $4-2^{\prime} \rightarrow 4-6^{\prime}$ & 538.0 & 452.9 \\
\hline Path 5 & $5-2 \rightarrow 4-6$ & -79.3 & -170.6 \\
\hline
\end{tabular}

3.6.3. Dynamics analysis of the decomposition and subsequent reactions

Fig. 6 shows the sectional drawing of the energy profile within each decomposition pathways. In Path 1, reactant 1-2 is converted to intermediate 1-3 via the transition state $\mathrm{TS}_{1-1}$. The reaction is a decarbonylation reaction with an energy barrier of $19.1 \mathrm{~kJ} / \mathrm{mol}$. The energy released by the decomposition reaction is $31.5 \mathrm{~kJ} / \mathrm{mol}$. Compound $1-3$ can be further decomposed through two competitive reaction pathways. At this time, the substituents on the benzene ring that will undergo the ring-opening reaction are located on the 2, 3, and 5 carbon atoms. The first reaction pathway is to form the intermediates $1-4$ via $\mathrm{TS}_{1-2}$ through the ringopening reaction with the bond between 1 and $2 \mathrm{C}$ atoms is broken, and the energy barrier is 
$285.6 \mathrm{~kJ} / \mathrm{mol}$; the second reaction pathway is the formation of intermediate $1-5$ via $\mathrm{TS}_{1-3}$ through the ring-opening reaction with the bond between 1 and 6 carbon atoms is broken, and the energy barrier is $172.9 \mathrm{~kJ} / \mathrm{mol}$. Comparing the energy barriers of the two reaction pathways, it can be seen that the energy barrier of the second reaction pathway $\left(1-3 \rightarrow \mathrm{TS}_{1}\right.$ $3 \rightarrow 1-5)$ was lower and the bond between 1 and 6 carbon atoms is relatively weak. The first reaction pathway was endothermic, which would absorb $156.1 \mathrm{~kJ} / \mathrm{mol}$ energy, and the second reaction pathway was exothermic, which could release $86.4 \mathrm{~kJ} / \mathrm{mol}$ energy. Intermediates 1-4 and 1-5 were decomposed into product 1-6 and by-product $\mathrm{CO}$ through decarbonylation. Therefore, considering the energy barrier analysis, the optimal reaction pathway for Path 1 was $1-2 \rightarrow 1-3 \rightarrow 1-5 \rightarrow 1-6$. During the real gasification process, the reaction is most likely to take place as this optimal reaction pathway. In addition, analysis of the entire reaction path reveals that the energy barrier of the ring-opening reaction is significantly higher than that of the decarbonylation reaction, This indicates that the decarbonylation reaction can quickly complete with a high conversion rate, while the ring-opening reaction is relatively slow. Therefore, the ring-opening reaction is the key reaction to control the reaction rate.

Fig.5 (b), (c) and (d) show the reaction path of Path 2, Path 3 and Path 4, respectively. From the conversion pathway diagrams, it can be seen there are two active sites in each Path and the reaction route was similar to that of Path 1 . The reactants were decomposed into respective transition states through the decarbonylation reaction, and then the intermediates were converted from the transition state form intermediates via a transition state through the ring-opening reaction. The intermediates were finally decomposed to the final products. Fig.6 (b), (c) and (d) presented the energy barriers of transition state from Path 2, Path 3 and Path 4 respectively. For Path 2, it can be seen that the energy barrier of $\mathrm{TS}_{2-2}$ was lower than that of $\mathrm{TS}_{2-3}$, which was $451.1 \mathrm{~kJ} / \mathrm{mol}$, while the energy barrier of $\mathrm{TS}_{2-2}$, was lower than that of $\mathrm{TS}_{2-3}$, which was $413.8 \mathrm{~kJ} / \mathrm{mol}$. The energy barrier of $\mathrm{TS}_{2-2}$, was lower than that of $\mathrm{TS}_{2-2}$ 
by comparison. This indicated that the optimal reaction pathway for Path 2 was $2-2$ ' $\rightarrow 2$ 3' $\rightarrow 2-4$ ' $\rightarrow 2-6$ '. For Path 3 and Path 4 , the reaction pathway was the same as Path 2 , hence the optimal reaction pathway for Path 3 and Path 4 are $3-2^{\prime} \rightarrow 3-3^{\prime} \rightarrow 3-4{ }^{\prime} \rightarrow 3-6^{\prime}$ and $4-2^{\prime} \rightarrow 4-$ 3' $\rightarrow$ 4-4' $\rightarrow$ 4-6', respectively. These optimal paths are considered to be the most likely reaction direction to occur during the gasification reaction. In these paths, the substituents on the benzene ring of the ring-opening reaction of intermediates 2-3 and 2-3 are located at carbon atoms 2 and 3, and the substituents of intermediate 4-3 are located at carbon atoms 2, 3 and 5. The substituents of intermediates 3-3 and 4-3 are located at carbon atoms 3 and 4, and the substituents of intermediate 3-3 are located at carbon atoms 2, 3, 4 and 5. When the substituents on the benzene ring of the ring-opening reaction are located in carbon atoms 2 and 3 and carbon atoms 2, 3 and 5, the C-C bond between carbon atoms 1 and 6 is always weaker than that between carbon atoms 1 and 2. Comparing the three reaction paths as a whole, the common characteristics could be derived. The energy barrier of the ring-opening reaction is significantly higher than that of decarbonylation reaction. This indicates that the ring-opening reactions were the key reactions that drove and controlled the reaction rate in the three reaction paths.

In Path 5, reactant 5-1 was decomposed into intermediate 5-3 via transition state $\mathrm{TS}_{5-1}$ with an energy barrier of $30.2 \mathrm{~kJ} / \mathrm{mol}$. The intermediate $5-3$ was further decomposed in two different pathways with the same way of Path 1. Comparing the two pathways, the energy barrier of pathway (5-3 $\rightarrow 5-5)$ was lower than that of the other, which is $236.2 \mathrm{~kJ} / \mathrm{mol}$. Ultimately, the intermediate 5-4 and 5-5 were decomposed into product 5-6 and by-product CO, giving the optimal reaction pathway for Path 5 being $5-2 \rightarrow 5-3 \rightarrow 5-5 \rightarrow 5-6$. In this reaction path, the substituents on the benzene ring of intermediate 5-3 are located at 2, 3 and 5 carbon atoms, which is the same as that obtained before. The $\mathrm{C}-\mathrm{C}$ bonds between 1 and 6 carbon atoms are more prone to homolysis than those between 1 and 2 carbon atoms. At the 
same time, it can be found that the energy barrier forming the first $\mathrm{CO}$ was significantly lower than the energy barrier forming the second $\mathrm{CO}$, which was the same to other reaction paths.

Summarizing the comparison among the five subsequent reaction paths, the optimal reaction paths were identified. A comprehensive comparison of the energy barriers of the five best reaction paths indicated that path 1 had the lowest energy barrier of $141.7 \mathrm{~kJ} / \mathrm{mol}$ and path 2 had the highest energy barrier of $918.0 \mathrm{~kJ} / \mathrm{mol}$. The order of the calculation results of energy barrier in each gasification reaction was: path 1 <path 5 <path 3 <path 4 <path 2 . This result is consistent with the calculation result of $\Delta G$. It can be further deduced that $\mathrm{CO}$ is mainly produced by Path 1 , when the gasification temperature is relatively low; while $\mathrm{CO}$ is mainly produced by Path 2 when the gasification temperature exceeded the $800{ }^{\circ} \mathrm{C}$.

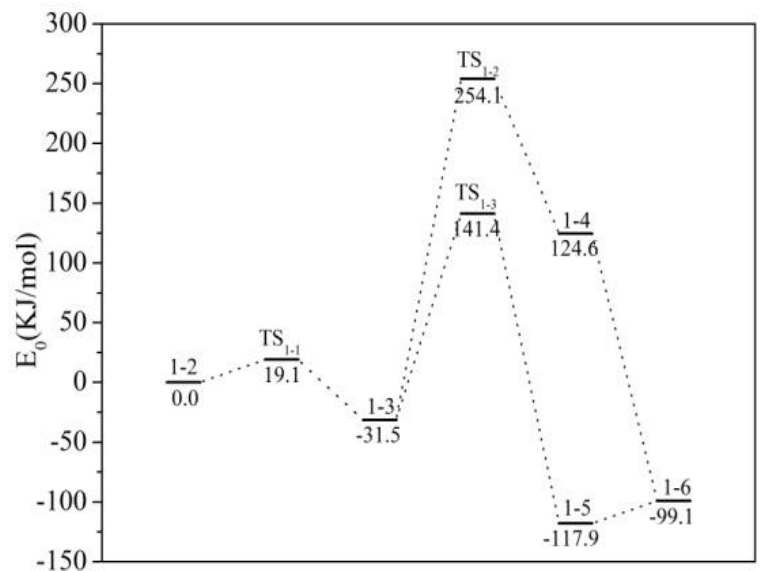

(a) Path 1

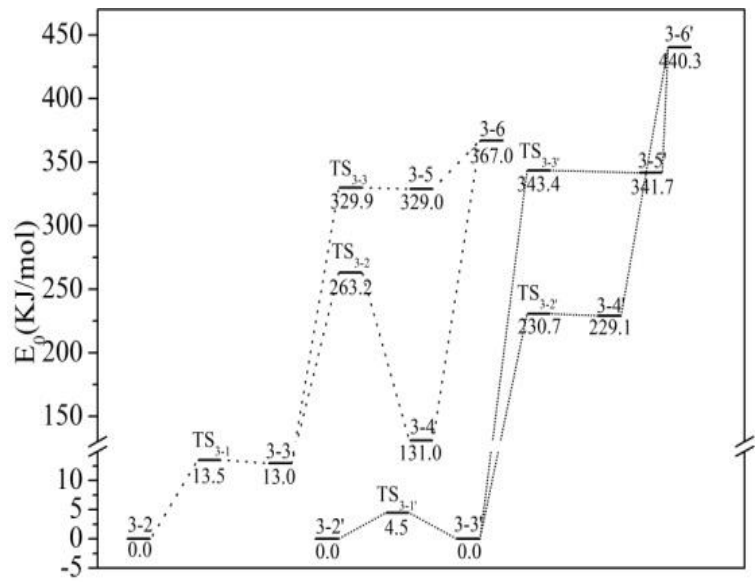

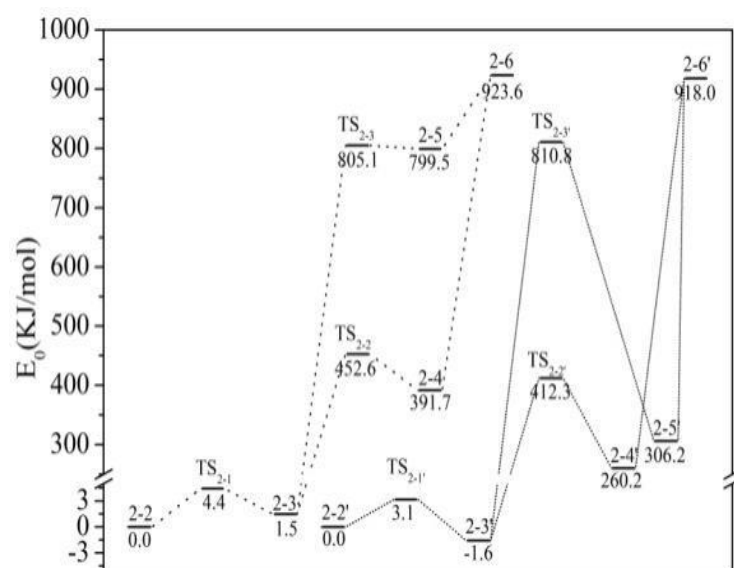

(b) Path 2

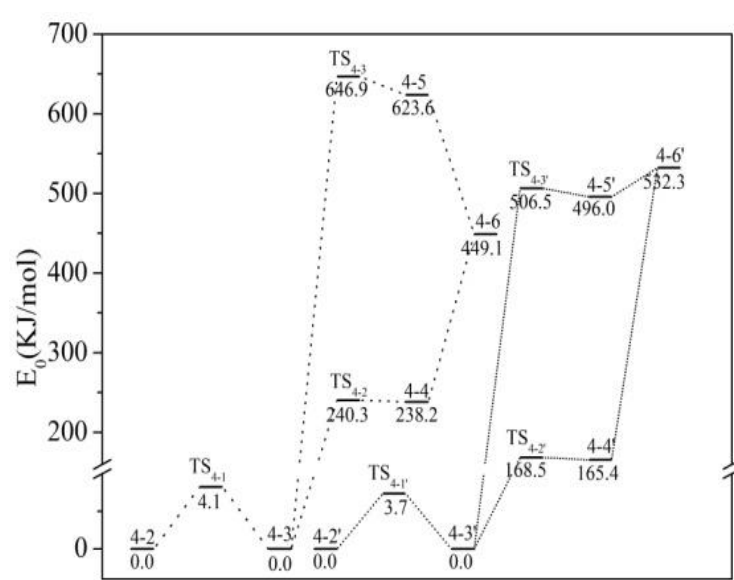




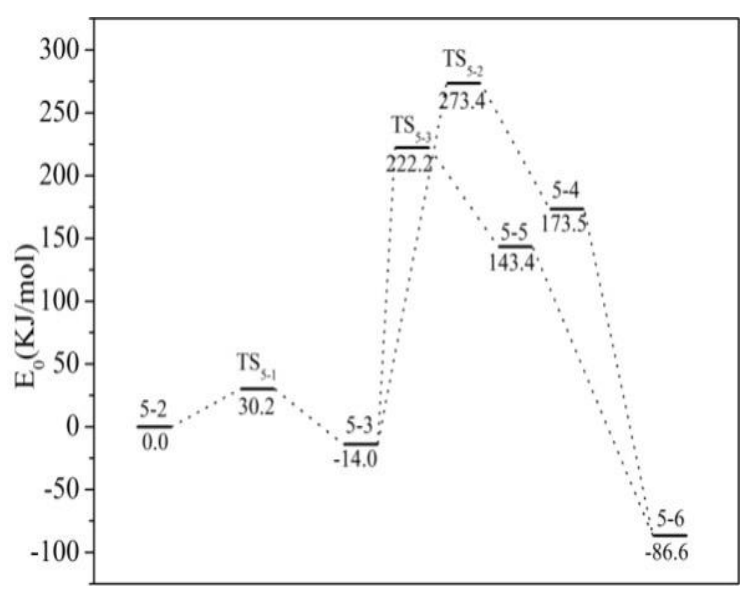

(e) Path 5

Fig.6 The potential energy profile of the decomposition reaction pathways

\section{Conclusion}

In this paper, the 2D molecular structure of Miscanthus derived biochar were developed and the gasification mechanism under the $\mathrm{CO}_{2}$ environment was investigated by applying DFT method at B3LYP/6-31G(d,p) level. One initial gasification pathway and five subsequent pathways were proposed. The $\Delta H$ and $\Delta G$ of five subsequent pathways were calculated and discussed. The activation energy of each reaction was studied. The key conclusions are:

- The empirical molecular formula of biochar was determined to be $\mathrm{C}_{77} \mathrm{H}_{44} \mathrm{O}_{11}$. The molecular structure model of biochar was formed by aromatic structure with functional groups including aliphatic carbon, carboxyl group, phenolic hydroxyl group, and aldehydes.

- Path 1 and path 5 can occur spontaneously during gasification process. The order of the reaction path, in terms of the degree of difficulty, was Path $1<$ Path $5<$ Path $3<$ Path $4<$ Path 2. 
- In the gasification process, for the benzene ring which undergoes ring-opening reaction, when the substituents are located in 2 and 3 carbon atoms or 2, 3 and 5 carbon atoms, the $\mathrm{C}-\mathrm{C}$ bond between 1 and 6 carbon atoms is more prone to homolytic reaction than that between 1 and 2 carbon Atoms.

\section{Supporting Information}

Partial geometric structure and key structure parameter optimization for the discussion in Section 3.6

\section{Acknowledgement}

This work was supported by the Natural Science Foundation of China for Young Scholars (No.51706022), the Natural Science Foundation of Hunan Province of China for Young Scholars (No.2018JJ3545), Open Fund of Key Laboratory of Renewable Energy Electric-Technology of Hunan Province (No.2017ZNDL007), 2019 Graduate Research and Innovation Project at Changsha University of Science and Technology (No. CX2019SS22) and the Innovative Team of Key Technologies of Energy Conservation, Emission Reduction and Intelligent Control for Power-Generating Equipment and System at CSUST. The authors also would like to acknowledge the funding from EU Horizon 2020 Research and Innovation Program under the Marie Skłodowska-Curie Action (Grant Agreement No. 823745).

\section{References}

1. Bouraoui, Z.; Dupont, C.; Jeguirim, M.; Limousy, L.; Gadiou, R., CO2 gasification of woody biomass chars: The influence of K and Si on char reactivity. Comptes Rendus Chimie 2016, 19 (4), 457465.

2. He, Q.; Guo, Q.; Ding, L.; Wei, J.; Yu, G., $\mathrm{CO}_{2}$ gasification of char from raw and torrefied biomass: Reactivity, kinetics and mechanism analysis. Bioresource Technology 2019, 293, 122087-122095. 3. Tong, W.; Liu, Q.; Yang, C.; Cai, Z.; Wu, H.; Ren, S., Effect of pore structure on $\mathrm{CO}_{2}$ gasification reactivity of biomass chars under high-temperature pyrolysis. Journal of the Energy Institute 2020, 93 ( 3), 962-976. 
4. Zhang, H.; Li, J.; Yang, X.; Song, S.; Wang, Z.; Huang, J.; Zhang, Y.; Fang, Y., Influence of coal ash on CO2 gasification reactivity of corn stalk char. Renewable Energy 2020, 147, 2056-2063.

5. Tian, H.; Jiao, H.; Cai, J.; Wang, J.; Yang, Y.; Bridgwater, A. V., Co-pyrolysis of Miscanthus Sacchariflorus and coals: A systematic study on the synergies in thermal decomposition, kinetics and vapour phase products. Fuel 2020, 262, 116603-116614.

6. Tian, H.; Hu, Q.; Wang, J.; Liu, L.; Yang, Y.; Bridgwater, A. V., Steam gasification of Miscanthus derived char: the reaction kinetics and reactivity with correlation to the material composition and microstructure. Energy Conversion and Management 2020, 219.

7. Bouraoui, Z.; Jeguirim, M.; Guizani, C.; Limousy, L.; Dupont, C.; Gadiou, R., Thermogravimetric study on the influence of structural, textural and chemical properties of biomass chars on CO2 gasification reactivity. Energy 2015, 88, 703-710.

8. Gupta, A.; Thengane, S. K.; Mahajani, S., CO2 gasification of char from lignocellulosic garden waste: Experimental and kinetic study. Bioresource Technology 2018, 263, 180-191.

9. Karlström, O.; Costa, M.; Brink, A.; Hupa, M., CO2 gasification rates of char particles from torrefied pine shell, olive stones and straw. Fuel 2015, 158, 753-763.

10. Izaharuddin, A. N.; Paul, M. C.; Yoshikawa, K.; Theppitak, S.; Dai, X., Comprehensive Kinetic Modeling Study of CO2 Gasification of Char Derived from Food Waste. Energy \& Fuels 2020, 34 (2), 1883-1895.

11. Wang, G.; Zhang, J.; Shao, J.; Liu, Z.; Wang, H.; Li, X.; Zhang, P.; Geng, W.; Zhang, G., Experimental and modeling studies on CO2 gasification of biomass chars. Energy 2016, 114, 143-154.

12. Sendt, K.; Haynes, B. S., Density functional study of the reaction of O2 with a single site on the zigzag edge of graphene. Proceedings of the Combustion Institute 2011, 33 (2), 1851-1858.

13. Huang, X.; Cheng, D.-g.; Chen, F.; Zhan, X., Reaction pathways of hemicellulose and mechanism of biomass pyrolysis in hydrogen plasma: A density functional theory study. Renewable Energy 2016, 96, 490-497.

14. Zhang, H.; Deng, S.; Cao, X., Density functional theory investigation of gasification mechanism of a lignin dimer with $\beta-5$ linkage. Renewable Energy 2018, 115, 937-945.

15. Zhao, D.; Liu, H.; Sun, C.; Xu, L.; Cao, Q., DFT study of the catalytic effect of Na on the gasification of carbon--CO2. Combustion and Flame 2018, 197, 471-486.

16. Shen, F.; Liu, J.; Zhang, Z.; Dong, Y.; Gu, C., Density functional study of hydrogen sulfide adsorption mechanism on activated carbon. Fuel Processing Technology 2018, 171, 258-264.

17. Xiao, X.; Chen, B., A Direct Observation of the Fine Aromatic Clusters and Molecular Structures of Biochars. Environ Sci Technol 2017, 51 (10), 5473-5482.

18. Xiao, X.; Chen, Z.; Chen, B., H/C atomic ratio as a smart linkage between pyrolytic temperatures, aromatic clusters and sorption properties of biochars derived from diverse precursory materials. Sci Rep 2016, 6, 22644.

19. Zhao, N.; Lv, Y.; Yang, X.; Huang, F.; Yang, J., Characterization and 2D structural model of corn straw and poplar leaf biochars. Environmental Science and Pollution Research 2017, 25 (26), 25789- 
25798.

20. Jiao, W.; Wang, Z.; Jiao, W.; Li, L.; Zuo, Z.; Li, G.; Hao, Z.; Song, S.; Huang, J.; Fang, Y., Influencing factors and reaction mechanism for catalytic $\mathrm{CO}_{2}$ gasification of sawdust char using $\mathrm{K}$ modified transition metal composite catalysts: Experimental and DFT studies. Energy Conversion and Management 2020, 208, 112522-112533.

21. Alejandro Montoya , F. M., Thanh N Truong, $\mathrm{CO}_{2}$ adsorption on carbonaceous surfaces: a combined experimental and theoretical study. Carbon 2003, 41 (1), 29-39.

22. Dang, Y.; Zhao, L.; Lu, X.; Xu, J.; Sang, P.; Guo, S.; Zhu, H.; Guo, W., Molecular simulation of $\mathrm{CO} 2 / \mathrm{CH} 4$ adsorption in brown coal: Effect of oxygen-, nitrogen-, and sulfur-containing functional groups. Applied Surface Science 2017, 423, 33-42.

23. Yang, G. X.; Jiang, H., Amino modification of biochar for enhanced adsorption of copper ions from synthetic wastewater. Water Res 2014, 48, 396-405.

24. Radovic, L. R., The mechanism of $\mathrm{CO} 2$ chemisorption on zigzag carbon active sites: A computational chemistry study. Carbon 2005, 43 (5), 907-915.

25. Alejandro Montoya, T.-T. T. T., Fanor Mondrago' n, Thanh N. Truong, CO Desorption from Oxygen Species on Carbonaceous Surface Effects of the LocalStructure of the Active Site and the Surface Coverage. The Journal of Physical Chemistry A 2001, 105 (27), 6757-6764.

26. Li, G.-Y.; Li, A.-Q.; Zhang, H.; Wang, J.-P.; Chen, S.-Y.; Liang, Y.-H., Theoretical study of the CO formation mechanism in the CO2 gasification of lignite. Fuel 2018, 211, 353-362.

27. Roberts, M. J.; Everson, R. C.; Domazetis, G.; Neomagus, H. W. J. P.; Jones, J. M.; Van Sittert, C. G. C. E.; Okolo, G. N.; Niekerk, D. V.; Mathews, J. P., Density functional theory molecular modelling and experimental particle kinetics for CO2-char gasification. Carbon 2015, 93, 295-314.

28. Montoya, A., Fanor Mondragón, T. N. Truong . Formation of $\mathrm{CO}$ precursors during char gasificationwith O2,CO2and H2O. Fuel Processing Technology 2002, 77-78 (25), 125-130.

29. Montoya, A., Mondragon, F., \& Truong, T. N., First-principles kinetics of CO desorption from oxygen species on carbonaceous surface. The Journal of Physical Chemistry A 2002, 106 (16), 4236-4239.

30. Hunt, J.; Ferrari, A.; Lita, A.; Crosswhite, M.; Ashley, B.; Stiegman, A. E., Microwave-Specific Enhancement of the Carbon-Carbon Dioxide (Boudouard) Reaction. The Journal of Physical Chemistry C 2013, 117 (51), 26871-26880.

31. Schuchardt, K. L., Didier, B. T., Elsethagen, T., Sun, L., Gurumoorthi, V., Chase, J., Windus, T. L., Basis set exchange: a community database for computational sciences. Journal of chemical information and modeling 2007, 47 (3), 1045-1052.

32. Najafi, M.; Nazarparvar, E.; Mood, K. H.; Zahedi, M.; Klein, E., DFT/B3LYP study of the substituent effects on $\mathrm{OH}$ bond dissociation enthalpies of chroman derivatives in the gas phase and solvent environment. Computational and Theoretical Chemistry 2011, 965 (1), 114-122.

33. Legler, C. R.; Brown, N. R.; Dunbar, R. A.; Harness, M. D.; Nguyen, K.; Oyewole, O.; Collier, W. B., Scaled Quantum Mechanical scale factors for vibrational calculations using alternate polarized and augmented basis sets with the B3LYP density functional calculation model. Spectrochim Acta A Mol 
Biomol Spectrosc 2015, 145, 15-24.

34. Watney, J. B.; Soudackov, A. V.; Wong, K. F.; Hammes-Schiffer, S., Calculation of the transition state theory rate constant for a general reaction coordinate: Application to hydride transfer in an enzyme. Chemical Physics Letters 2006, 418 (1-3), 268-271.

35. Piansawan, T.; Kungwan, N.; Jungsuttiwong, S., Application of the reaction class transition state theory to the kinetics of hydrogen abstraction reactions of alkanes by atomic chlorine. Computational and Theoretical Chemistry 2013, 1011, 65-74.

36. Meng, F.; Yu, J.; Tahmasebi, A.; Han, Y.; Zhao, H.; Lucas, J.; Wall, T., Characteristics of Chars from Low-Temperature Pyrolysis of Lignite. Energy \& Fuels 2013, 28 (1), 275-284.

37. Fu, D.-q.; Li, X.-h.; Li, W.-y.; Feng, J., Catalytic upgrading of coal pyrolysis products over biochar. Fuel Processing Technology 2018, 176, 240-248.

38. Lin, X.; Wang, C.; Ideta, K.; Miyawaki, J.; Nishiyama, Y.; Wang, Y.; Yoon, S.; Mochida, I., Insights into the functional group transformation of a chinese brown coal during slow pyrolysis by combining various experiments. Fuel 2014, 118, 257-264.

39. Zhao, Y.; Feng, D.; Zhang, Y.; Huang, Y.; Sun, S., Effect of pyrolysis temperature on char structure and chemical speciation of alkali and alkaline earth metallic species in biochar. Fuel Processing Technology 2016, 141, 54-60.

40. Wang, S.; Jiang, D.; Cao, B.; Qian, L.; Hu, Y.; Liu, L.; Yuan, C.; Abomohra, A. E.-F.; He, Z.; Wang, Q.; Zhang, B., Bio-char and bio-oil characteristics produced from the interaction of Enteromorpha clathrate volatiles and rice husk bio-char during co-pyrolysis in a sectional pyrolysis furnace: A complementary study. Journal of Analytical and Applied Pyrolysis 2018, 135, 219-230.

41. Lahijani, P.; Zainal, Z. A.; Mohammadi, M.; Mohamed, A. R. J. R.; Reviews, S. E., Conversion of the greenhouse gas CO_2 to the fuel gas $\mathrm{CO}$ via the Boudouard reaction: A review. 2015, 41, 615-632.

42. Sikarwar, V. S., Zhao, M., Clough, P., Yao, J., Zhong, X., Memon, M. Z., Fennell, P. S. , An overview of advances in biomass gasification. Energy \& Environmental Science 2016, 9 (10), 2939-2977. 


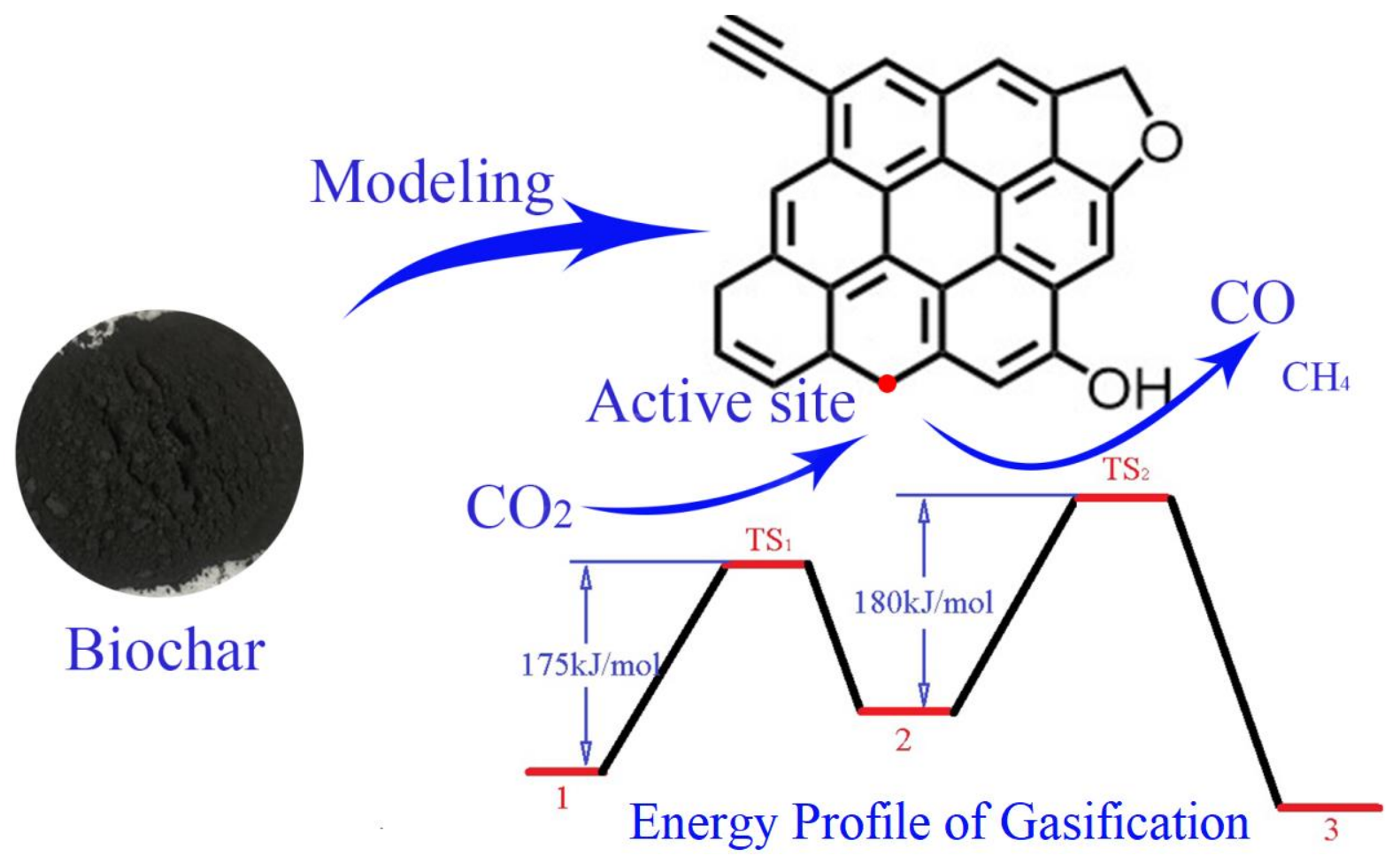

